\title{
What has happened to patients from long-stay psychiatric wards?
}

\author{
D. B. Double, Lecturer in Psychiatry, University of Sheffield, Northern General \\ Hospital, Sheffield S5 7AU; and T. I. WoNG, Registrar in Psychiatry, Sheffield \\ Rotational Training Scheme, Middlewood Hospital, Sheffield S6 ITP
}

Evidence bearing on the issue of what happens to patients from long-stay psychiatric wards in Britain is scarce. The results of a particularly well-planned resettlement programme may not be representative of the outcome from general policies of discharge from all psychiatric hospitals. The present study was undertaken in Sheffield to find the whereabouts of patients from long-stay wards after eight years, a longer period than usually studied previously. The expectation was that difficulties in tracing patients could be overcome with sufficient time and effort.

\section{The study}

Middlewood Hospital is a traditional psychiatric hospital now serving the Sheffield Health District. Before computerisation of medical records an occasional census of in-patients - about every two years was undertaken to produce the nominal roll of patients. Information from the census taken on 12 January 1982 had been kept intact and formed the starting point for follow-up of patients on wards designated as long-stay. Psychogeriatric wards were not included.

A clear line of continuity from these long-stay wards to the rehabilitation and long-stay service at the time of follow-up in 1990 could be traced. The number of wards in the service has been reduced from 17 to 11 (including two smaller rehabilitation hostel wards). Only four of these wards were used for longstay patients in both 1982 and 1990.

The whereabouts of all patients was ascertained as at 12 January 1990 , i.e. exactly eight years later. Obviously certain patients were easier to trace than others. Some were still in-patients, others had died in hospital or been discharged. Information about those discharged was often the most difficult to obtain but persistence in following leads from staff contacts and medical records enabled all patients to be found.

\section{Findings}

The number of in-patients in the rehabilitation and long-stay service at the time of the census in 1982 was 438. At follow-up eight years later the number of in-patients had been reduced to 232 (a $47 \%$ reduction in in-patient numbers). Of these 232 patients, 171 $(74 \%)$ had been in-patients eight years previously and $61(26 \%)$ had been newly admitted.

The average age of patients in the sample was 62 years, which is less than the average age of 65 years of patients in the rehabilitation and long-stay service at the time of follow-up.

The whereabouts of all patients was traced. The highest proportion $(42 \%)$ were still in hospital, not necessarily Middlewood; $35 \%$ had died, although not necessarily in hospital; and $23 \%$ were in nonhospital settings.

Of those in hospital, 171 were still in the rehabilitation and long-stay services. Fourteen were in other wards or hospitals: two in psychogeriatric wards in Middlewood; one was on an acute admission ward at the time of follow-up; four were in secure facilities (two at St Andrews Hospital, Northampton and two in Rampton); one was in a psychiatric hospital in Carlisle; and six were in hospital in Rotherham (five on psychogeriatric wards, one on a rehabilitation ward), whose health authority had agreed to take responsibility for these long-stay patients after health service reorganisation.

Of the 100 patients living in non-hospital settings, the majority were in residential or group homes. Only 26 of those outside hospital $(6 \%$ of original sample of 438 patients) were living at their own address or with relatives. The greatest number (36) were in residential homes for the elderly (Part III), 15 of whom had been resettled in the few months before the survey as part of a project transferring funding to the local authority. Twenty were in private residential care for the mentally ill. The others were in private residential care for the elderly (1), local authority homes for the mentally ill (4), Sheffield hostel for homeless men (2) and group homes (10). One person was in prison but none were homeless.

\section{Comment}

This study has demonstrated that with perseverance discharged patients from long-stay psychiatric wards 
can be traced, at least in Sheffield. The situation may be different in larger cities such as London, for example. Only two patients from the sample had moved outside the local area.

No patients were homeless at follow-up. This finding may suggest some caution is needed in interpreting studies that suggest a high level of mental illness among the homeless as implying that the rundown of the psychiatric hospital should be slowed. A poorly reasoned polemic from Weller (1989) can find its way into the prestigious columns of Nature, revealing the current bias against deinstitutionalisation in Britain. The present study gives some picture of what actually happens to patients after discharge.

It is important to note the high rate of death among this patient group. The long-stay population in psychiatric hospitals is elderly. The rehabilitation and long-stay service in Sheffield at follow-up eight years later has a slightly increased average age. If there are no further admissions a significant attrition rate through death can continue to be expected. It is important to remember that the decline in the number of patients in psychiatric hospitals is not only due to discharge but to death expected because of the age distribution of the longstay population.

Of those discharged from hospital the majority were still living in fairly institutional surroundings. A significant proportion of this care in Sheffield is provided in private residential homes for the mentally ill. The person who was in prison was there for attempted murder and was not regarded as mentally ill.
The quality of life issue for those out of hospital compared with those remaining in hospital has not been answered by this study. Nor could it easily be answered because of the difficulty measuring quality of life, obtaining adequate control groups, and the lack of randomisation. Those who are resettled are selected to some extent, making the interpretation of any comparison with those remaining in hospital difficult.

If problems are being caused by the rundown of the psychiatric hospital, it may be because of the limited facilities for the new long-stay, rather than because of the resettlement of the older long-stay patients. Any argument about community care and the preservation of the traditional psychiatric hospital should distinguish between the needs of people who can no longer get into the psychiatric system, as opposed to the needs of the people who may just have been thrown out. However, a substantial proportion of the rehabilitation and long-stay wards in this study at follow-up were occupied by newly admitted patients over the eight years since the census.

Government policy is moving in the direction of smaller units for continuous care of psychiatric patients. The relatively small group of patients placed outside hospital over eight years could suggest there is scope for more, not less, resettlement of patients from the traditional psychiatric hospital.

\section{Reference}

WeLLER, M. P. I (1989) Mental illness - who cares? Nature, $339,249-252$

\section{Absconders from a district general hospital}

\section{B. T. FARID, Consultant Psychiatrist, New Cross Hospital, Wolverhampton WV10 0QP}

The patient absconding without leave (AWOL) produces considerable anxiety to staff, relatives and the public, and involves a great deal of staff time in notification, search and enquiry to the detriment of the care of other patients. Incidents of AWOL are potentially dangerous and all efforts to predict these incidents and to deal with them appropriately should be made.

\section{The study \\ Aims}

(a) To find out the pattern of AWOL incidents at New Cross Hospital Psychiatric Unit including characteristics of the patients and any possible variables that will assist in predicting them. 